\title{
УДК 657
}

\section{О. Н. Свешникова}

ФГБОУ ВО «Национальный исследовательский Мордовский государственный университет имени Н.П. Огарёва», Саранск, e-mail: svesholga@yandex.ru

\section{О. Н. Лебедева}

ФГБОУ ВО «Национальный исследовательский Мордовский государственный университет имени Н.П. Огарёва», Саранск, е-mail: olga.lebedeva.1997@yandex.ru

\section{ОЦЕНКА НЕФИНАНСОВЫХ АКТИВОВ В ФЕДЕРАЛЬНЫХ И МЕЖДУНАРОДНЫХ СТАНДАРТАХ БУХГАЛТЕРСКОГО УЧЕТА И ОТЧЕТНОСТИ}

Ключевые слова: оценка, нефинансовые активы, федеральные стандарты, международные стандарты, справедливая стоимость, признание, бухгалтерская отчетность.

Реформа системы регулирования бухгалтерского учета, методологической концепцией которой выступает сближение отечественной системы нормативных документов по бухгалтерскому учету в организациях госсектора с требованиями международных стандартов финансовой отчетности общественного сектора (МСФО ОС), длится в России уже два десятилетия. За это время учет и отчетность в секторе государственного управления претерпели значительные изменения, вступив в настоящий момент на качественно новый уровень реформирования. С 1 января 2018 года учет в госучреждениях строится на положениях федеральных стандартов. В этой связи большой интерес представляет сравнительный анализ регламентаций международных и отечественных стандартов. В статье представлены результаты исследования положений по оценке нефинансовых активов организаций госсектора, содержащиеся в федеральных и международных стандартах бухгалтерского учета и отчетности. Выявлены общность и различия в оценке активов при нахождении их на разных стадиях жизненного цикла в учреждении. Дана оценка новации расширения сферы применения справедливой стоимости.

\section{O. N. Sveshnikova}

National Research Mordovia N.P. Ogarev State University, Saransk, e-mail: svesholga@yandex.ru

\section{O. N. Lebedeva}

National Research Mordovia N.P. Ogarev State University, Saransk, e-mail: olga.lebedeva.1997@yandex.ru

\section{ASSESSMENT OF NON-FINANCIAL ASSETS IN FEDERAL AND INTERNATIONAL ACCOUNTING AND REPORTING STANDARDS}

Keywords: assessment, non-financial assets, federal standards, international standards, fair value, recognition, financial reporting.

The reform of the accounting regulatory system, the methodological concept of which is the convergence of the national system of normative documents on public sector accounting with the International Public Sector Accounting Standards (IPSAS), has been going on in Russia for two decades. During this time, accounting in the public sector has undergone significant changes, now entering a qualitatively new stage of reform. Since January 1, 2018, accounting in public sector organizations is based on the provisions of federal standards. In this regard, a comparative analysis of the regulations of international and national standards is of great interest. The article presents the results of a study of the provisions on the assessment of non-financial assets of public sector organizations contained in federal and international accounting and reporting standards. The article contains similarities and differences in the assessment of assets when they are at different stages of the life cycle in the institution. The assessment of the innovation of expanding the scope of application of fair value is given.

\section{Введение}

Как известно, с 1 января 2018 года бухгалтерский учет в государственных учреждениях РФ строится на положени- ях федеральных стандартов бухгалтерского учета для организаций государственного сектора (далее - СГС), ориентиром для разработки которых стали 
МСФО общественного сектора. Одними из первых были приняты стандарты, раскрывающие порядок формирования информации о некоторых объектах нефинансовых активов.

Программой разработки федеральных стандартов бухгалтерского учета для организаций госсектора на 20192021 гг. предусмотрено принятие еще двух стандартов, касающихся нефинансовых активов - «Нематериальные активы» и «Биологические активы». На наш взгляд, первоочередное введение в практику учета стандартов по нефинансовым активам объясняется тем, что от того, какое имущество находится в управлении учреждения, насколько полно и эффективно оно используется, зависит и качество оказываемых услуг.

\section{Цель исследования}

Целью научного исследования является установление общности и различий в применяемых оценках нефинансовых активов государственных учреждений, предусмотренных отечественными и международными стандартами бухгалтерского учета.

\section{Материал и методы исследования}

В процессе исследования положений федеральных и международных стандартов были использованы такие методы, как систематизация, аналогия, абстрагирование, сравнение, обобщение. Информационной базой послужили нормативно-правовые документы и научные статьи.

\section{Результаты исследования и их обсуждение}

Следует отметить, что в СГС встречается понятие нефинансовых активов, однако его содержание не раскрывается. При этом в действующих формах бухгалтерской отчетности, составляемой организациями госсектора, активы представлены нефинансовыми и финансовыми. В МСФО ОС термин «нефинансовые активы» не применяется, вместо него краткосрочные активы. На сегодняшний день общее представление о нефинансовых активах содержится в Инструкции № $157 \mathrm{H}$.

В практике МСФО коммерческих организаций общие правила по со- ставлению бухгалтерской отчетности содержатся в одном документе, называемом Концептуальные основы представления финансовых отчетов. В нашей стране аналогичный документ в виде самостоятельного стандарта появился у организаций госсектора «Концептуальные основы бухгалтерского учета и отчетности организаций государственного сектора» [2]. Один из разделов стандарта содержит порядок оценки объектов бухгалтерского учета, однако на деле он полностью посвящен лишь одному виду оценки справедливой стоимости и методам ее определения. МСФО ОС не содержит аналогичного отдельного стандарта, а все виды оценок раскрываются в стандарте, посвященном соответствующему объекту учета.

Оценка как элемент бухгалтерского учета оказывает влияние на создаваемую им информацию. Как в отечественной, так и международной практике стандарты предусматривают многовариантность оценки объектов учета и отчетности. Правильно выбранная оценка влияет на величину имущественной массы учреждения, налогооблагаемую базу по налогу на имущество, финансовые показатели, используемые для оценки финансового состояния [12].

Приступая к раскрытию содержательного аспекта оценки нефинансовых активов, отметим, что выбор методологического подхода к ее определению зависит, прежде всего, от стадии жизненного цикла объекта учета в учреждении. Так, различают оценку актива в момент его появления в учреждении (в СГС это называется принятием к бухгалтерскому учету, в МСФО ОС - признанием) и последующую оценку или оценку после признания.

Обратимся к оценке основных средств госучреждений, которые обычно занимают наибольший удельный вес в их имущественном потенциале (таблица 1).

$\mathrm{B}$ соответствии с российскими правилами учета объекты нефинансовых активов при признании оцениваются по первоначальной стоимости. В МСФО ОС их оценка определяется понятием «себестоимость». Рассмотрим содержательный аспект этих оценок (таблица 2). 
Оценка основных средств в федеральном и международном стандартах

\begin{tabular}{|c|c|c|}
\hline Время определения оценки & СГС «Основные средства» & $\begin{array}{c}\text { МСФО ОС 17 } \\
\text { «Основные средства» }\end{array}$ \\
\hline При признании & Первоначальная стоимость & Себестоимость \\
\hline $\begin{array}{c}\text { После признания } \\
\text { / Последующая оценка }\end{array}$ & Балансовая стоимость & $\begin{array}{c}\text { Себестоимость / } \\
\text { Переоцененная стоимость }\end{array}$ \\
\hline
\end{tabular}

Таблица 2

Подходы к оценке основных средств при их признании

\begin{tabular}{|l|l|}
\hline \multicolumn{1}{|c|}{ СГС «Основные средства» } & \multicolumn{1}{|c|}{ МСФО ОС 17 «Основные средства» } \\
\hline $\begin{array}{l}\text { Первоначальная стоимость - стои- } \\
\text { мость, по которой актив принят субъ- } \\
\text { ектом учета к бухгалтерскому учету }\end{array}$ & $\begin{array}{l}\text { их эквивалентов или справедливая стоимость другого воз- } \\
\text { мещения, переданного в целях приобретения актива на мо- } \\
\text { мент его приобретения или создания }\end{array}$ \\
\hline
\end{tabular}

В международной и отечественной системе учета оценка объектов нефинансовых активов при признании зависит от способа их приобретения. Так, операции по приобретению основных средств делятся на обменные и необменные. В обменных операциях задействованы сопоставимые по денежной величине (стоимости) активы, в том числе денежные средства и их эквиваленты. Для необменных операций свойственна передача активов на безвозмездной основе или по ценам существенно ниже рыночных.

Обменные операции, в свою очередь, могут носить коммерческий либо некоммерческий характер. К коммерческим относят обменные операции, в результате которых в деятельности хозяйствующего субъекта возникает изменение денежных потоков или полезного потенциала [14].

Влияние способа приобретения на порядок формирования первоначальной стоимости основных средств представлено на рисунке 1.

Исключение составляют основные средства, полученные от собственников, первоначальная оценка которых соответствует сумме, отраженной в передаточных документах. Такой подход характерен только для российской практики.

Возвращаясь к рисунку 1, отметим, что нефинансовый актив, приобретенный путем необменной операции, оценивается по справедливой стоимости.
Данный вид оценки стал принципиально новым для отечественной системы бухгалтерского учета, в связи с чем его экономическое содержание представляет особый интерес.

Прежде всего, рассмотрим понятие справедливой стоимости в рамках российских и международных стандартов (таблица 3).

Как следует из таблицы 3, трактовка понятия, содержащаяся в федеральном стандарте, в целом соответствует международным правилам учета и отчетности, однако СГС, помимо всего прочего, содержит указание на переход права собственности на актив в результате сделки. Таким образом, данная оценка увязывается с «вещным» правом.

Системой федеральных стандартов предусмотрено формирование справедливой стоимости с использованием двух методов: метода рыночных цен и метода амортизированной стоимости замещения. Сущность первого из них заключается в оценке актива исходя из текущих рыночных цен или данных о недавних сделках с аналогичными или схожими активами, совершенных без отсрочки платежа [2]. При этом стандарт указывает, что под рыночной ценой актива следует понимать цену, которая может быть получена (уплачена) при продаже актива между независимыми сторонами сделки, осведомленными о предмете сделки и желающими ее совершить. Таким образом, Концептуальные осно- 
вы фактически приравнивают справедливую стоимость актива к его рыночной цене, тем самым подвергая сомнению возможность применения метода амортизированной стоимости [10].

МСФО ОС не содержит определенных требований касательно методов определения справедливой стоимости.
В то же время в МСФО коммерческих организаций для этих целей предусмотрен отдельный стандарт - MCФО (IFRS) 13 «Оценка справедливой стоимости». Согласно данному стандарту справедливая стоимость актива может быть определена с использованием рыночного, затратного либо доходного подхода.

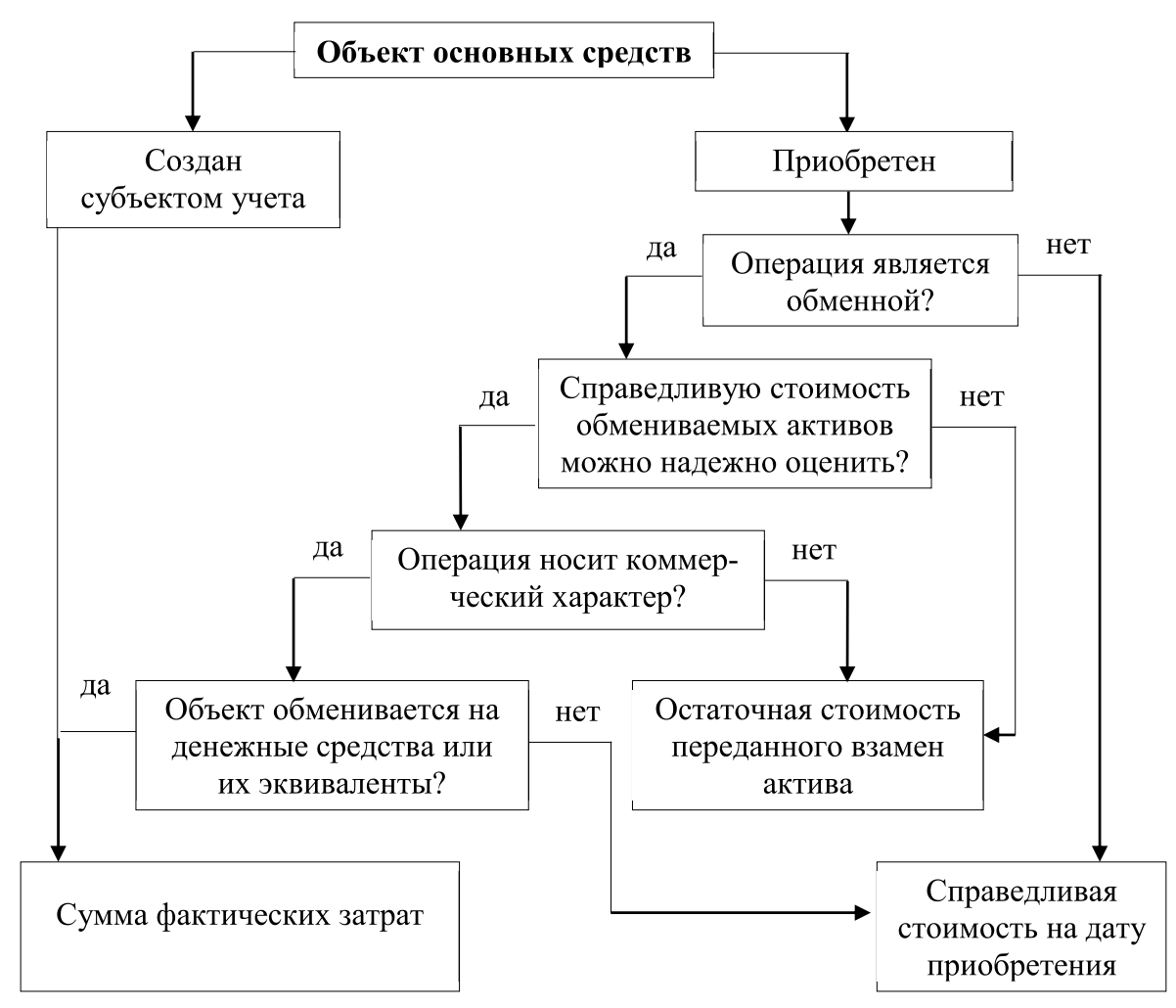

Рис. 1. Влияние способа приобретения на порядок формирования первоначальной стоимости основных средств

Таблица 3

Понятие справедливой стоимости в федеральных и международных стандартах

\begin{tabular}{|l|l|}
\hline \multicolumn{1}{|c|}{ СГС } & \multicolumn{1}{|c|}{ МСФО ОС } \\
\hline Справедливая стоимость-оценка, соответствующая & Справедливая стоимость - сумма, на которую \\
цене, по которой может быть осуществлен переход & можно обменять актив или погасить обязатель- \\
права собственности на актив между независимы- & ство при совершении сделки между хорошо ос- \\
ми сторонами сделки, осведомленными о предмете & ведомленными, желающими совершить такую \\
сделки и желающими ее совершить & сделку и независимыми друг от друга сторонами \\
\hline
\end{tabular}

Таблица 4

Последующая оценка основных средств

\begin{tabular}{|l|l|}
\hline \multicolumn{1}{|c|}{ СГС «Основные средства» } & \multicolumn{1}{|c|}{ МСФО ОС 17 «Основные средства» } \\
\hline $\begin{array}{l}\text { Балансовая стоимость - первоначальная } \\
\text { стоимость актива с учетом ее изменений }\end{array}$ & $\begin{array}{l}\text { Переоцененная стоимость - справедливая стоимость } \\
\text { на дату переоценки за вычетом накопленной аморти- } \\
\text { зации и убытков от обесценения }\end{array}$ \\
\hline
\end{tabular}


Если в отношении первоначальной оценки основных средств федеральные и международные стандарты едины в своем подходе, то последующая оценка таких активов имеет некоторые отличия (таблица 4).

На наш взгляд, присутствующий в федеральном стандарте вид оценки «балансовая стоимость» вносит путаницу, завуалировав необходимость переоценки основных средств в случае доведения до справедливой стоимости. Учитывая, что СГС раскрывает содержание изменений стоимости (достройка, дооборудование, техперевооружение, модернизация, разукомплектация, переоценка), вполне достаточно обойтись одним показателем - остаточная стоимость. МСФО ОС 17 открыто предлагает две модели оценки после признания: по себестоимости и по переоцененной стоимости.

Порядок учета и оценки непроизведенных активов раскрывается в СГС «Непроизведенные активы». В международных стандартах категория «непроизведенные активы» отсутствует. Земельные участки в соответствии с МСФО ОС могут относиться как к основным средствам, так и к инвестиционной недвижимости.
Первоначальная стоимость непроизведенных активов, к которым относятся земля, недра и иные природные ресурсы, равна справедливой стоимости на дату вовлечения в хозяйственный оборот [4]. Такая оценка, в свою очередь, зависит от объекта учета (рисунок 2).

В остальных случаях оценка объектов непроизведенных активов производится по тем же правилам, что и оценка основных средств, за исключением создания субъектом учета ввиду отсутствия такой возможности (рисунок 1).

После признания учет непроизведенных активов ведется по балансовой стоимости. Объекты непроизведенных активов подлежат ежегодной переоценке по справедливой стоимости, определяемой указанным на рисунке 3 способом.

Неотъемлемую часть имущества госучреждений составляют материальные запасы. Согласно СГС «Запасы» при признании данный вид активов оценивается по первоначальной стоимости. В МСФО ОС первоначальной оценкой запасов выступает наименьшая из двух величин: себестоимость или чистая цена продажи (таблица 5).

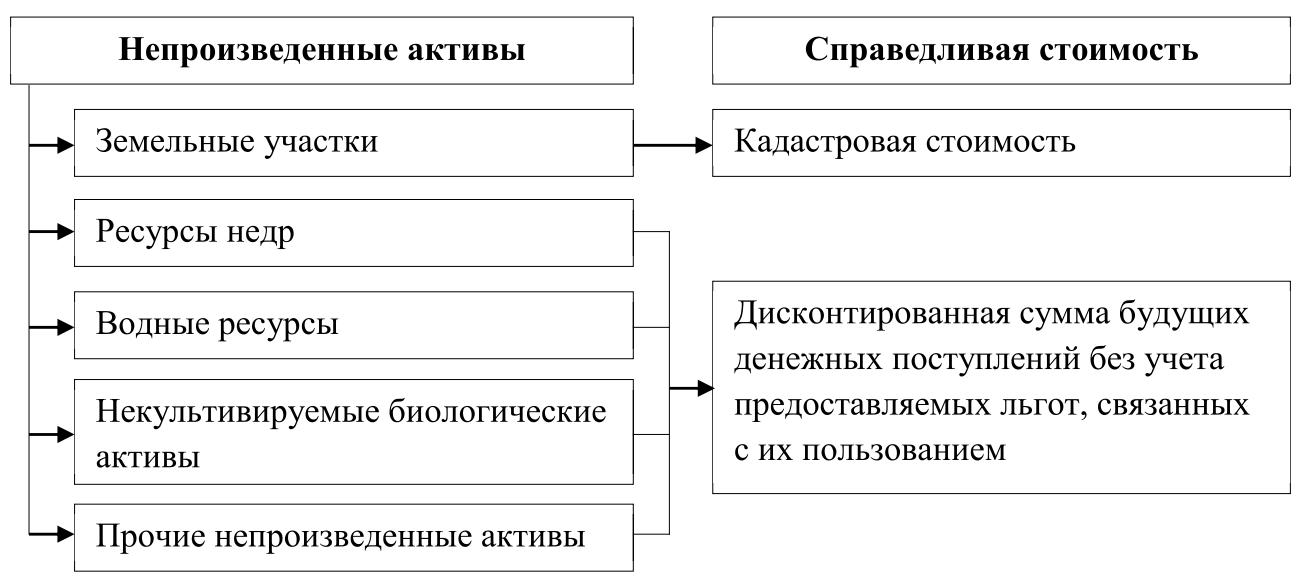

Рис. 2. Справедливая стоимость объектов непроизведенных активов

Таблица 5

Оценка запасов в федеральных и международных стандартах

\begin{tabular}{|c|c|c|}
\hline Время определения оценки & СГС «Запасы» & МСФО ОС 12 «Запасы» \\
\hline При признании & Первоначальная стоимость & Себестоимость \\
\hline После признания / & Первоначальная стоимость & Себестоимость \\
Последующая оценка & & / Чистая цена продажи \\
\hline
\end{tabular}




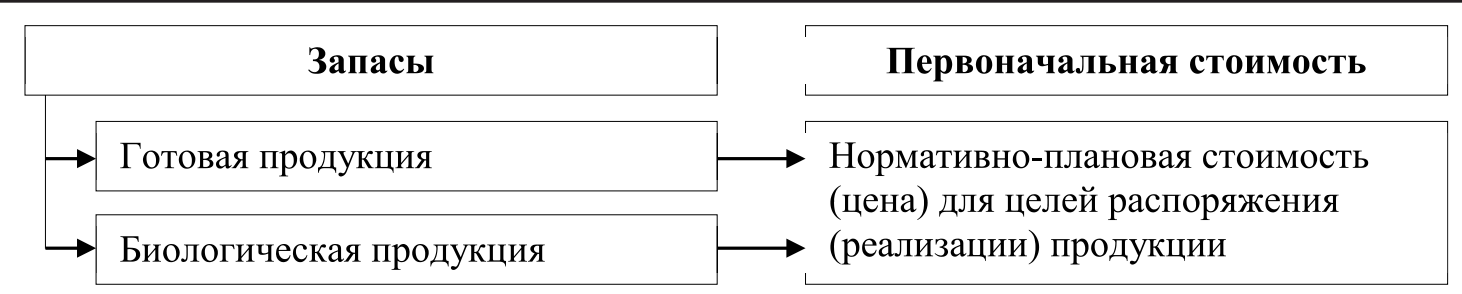

Рис. 3. Первоначальная стоимость готовой и биологической продукции

Существенное влияние на оценку запасов, как и других нефинансовых активов, оказывает характер операций, в результате которых объекты появляются в учреждении и условия приобретения. Так, активы, полученные в результате обменной операции коммерческого характера, при признании оцениваются по справедливой стоимости. В случае, когда активы обмениваются на денежные средства или их эквиваленты либо создаются субъектом учета, их первоначальная стоимость включает все фактически произведенные вложения.

Особый подход к формированию первоначальной стоимости характерен для готовой и биологической продукции на дату выпуска (риунок 3 ).

Согласно СГС запасы могут переоцениваться, но лишь те, по которым наблюдаются определенные изменения: предназначены для продажи, безвозмездной передачи, за плату по незначительным ценам; снизилась нормативно-плановая себестоимость и др. С учетом этого должен создаваться резерв под снижение стоимости запасов, который уменьшает величину признанной стоимости запасов при отражении в балансе.

В МСФО ОС для оценки запасов предусмотрено использование чистой цены продажи, то есть такой суммы, которую организация ожидает получить от продажи активов в ходе своей обычной деятельности [15]. Данный вид оценки в отличие от справедливой стоимости индивидуален для каждой организации.

В отношении запасов, приобретенных в ходе необменной операции, положения международных и российских стандартов едины - оценка таких активов при признании осуществляется по справедливой стоимости на дату приобретения. При этом справедливая стоимость согласно СГС «Запасы» может быть определена только методом рыночных цен.

\section{Выводы (заключение)}

Проведенный сравнительный анализ регламентаций международных и отечественных стандартов в отношении оценки нефинансовых активов показал наличие общего в методологии. Так, общепризнанно, что следует различать оценку при признании и последующую (после признания). Причем, в Концептуальных основах раскрывается содержание понятий «признание» и «прекращение признания», несмотря на неоднозначность формулировок.

Как в международном, так и в отечественном учете существенное влияние на оценку при признании оказывает способ приобретения объекта нефинансовых активов: обменный или необменный и, в первом случае, характер обмена - коммерческий или некоммерческий. Еще одним шагом в сторону сближения МСФО ОС и федеральных стандартов стало расширение границ применения справедливой стоимости активов, однако методы ее определения имеют различия. Также следует принять во внимание, что в процессе осуществления своей деятельности учреждения госсектора приобретают имущество (кроме внесенного учредителями в момент создания) по системе госзакупок, т.е. преобладающей первоначальной оценкой по-прежнему остается сумма фактических затрат.

Таким образом, введение новых видов оценки, методов их определения сближает российскую и международную системы бухгалтерской отчетности. Тем не менее, было бы целесообразно, обобщив правила оценки, представить их в едином документе, например, СГС «Концептуальные основы бухгалтер- 
ского учета и отчетности организаций государственного сектора». Кроме того, считаем необходимым однозначное определение понятий первоначальной и последующей оценки как оценки, обусловленной разными стадиями нахождения объекта учета, в частности активов, в учреждении.

\section{Библиографический список}

1. Приказ Минфина РФ от 1 декабря 2010 г. № 157н «Об утверждении Единого плана счетов бухгалтерского учета для органов государственной власти (государственных органов), органов местного самоуправления, органов управления государственными внебюджетными фондами, государственных академий наук, государственных (муниципальных) учреждений и Инструкции по его применению» (с изменениями и дополнениями) [Электронный ресурc]. URL: http://base.garant.ru/12180849/ (дата обращения: 04.10.2019 г.).

2. Приказ Минфина России от 31 декабря 2016 г. № 256н «Об утверждении федерального стандарта бухгалтерского учета бухгалтерского учета для организаций государственного сектора «Концептуальные основы бухгалтерского учета и отчетности организаций государственного сектора» (с изменениями и дополнениями) [Электронный ресурc]. URL:http://base.garant.ru/71586636/ (дата обращения: 04.10.2019 г.).

3. Приказ Минфина России от 31 декабря 2016 г. № 257н «Об утверждении федерального стандарта бухгалтерского учета для организаций государственного сектора «Основные средства» (с изменениями и дополнениями) [Электронный ресурc]. URL:http://base.garant.ru/71589050/ (дата обращения: 07.10.2019 г.)

4. Приказ Минфина России от 28 февраля 2018 г. № 34н «Об утверждении федерального стандарта бухгалтерского учета для организаций государственного сектора «Непроизведенные активы» (с изменениями и дополнениями) [Электронный ресурc]. URL: http://base.garant.ru/71948612/ (дата обращения 09.10.2019 г.).

5. Приказ Минфина России от 7 декабря 2018 г. № 256н «Об утверждении федерального стандарта бухгалтерского учета для организаций государственного сектора «Запасы» (с изменениями и дополнениями) [Электронный ресурс]. URL: https://base.garant.ru/72146396/ (дата обращения: 12.10.2019 г.).

6. Письмо Минфина России от 15 декабря 2017 г. № 02-07-07/84237 «О направлении Методических рекомендаций по применению федерального стандарта для организаций государственного сектора «Основные средства» [Электронный ресурс]. URL: https://base.garant.ru/71835182/ (дата обращения: 08.10.2019 г.).

7. Письмо Минфина России от 1 августа 2019 г. № 02-07-07/58075 «Методические рекомендации по применению федерального стандарта для организаций государственного сектора «Запасы» [Электронный ресурc]. URL: https://base.garant.ru/72267754/ (дата обращения: 13.10.2019 г.).

8. Проект Приказа Минфина России «Об утверждении федерального стандарта бухгалтерского учета для организаций государственного сектора «Нематериальные активы» (с изменениями и дополнениями) [Электронный ресурс]. URL: https://www.minfin.ru/ru/perfomance/budget/bu gs/sfo/ (дата обращения: 04.10.2019 г.).

9. Дружиловская Э.С. Теоретические и методологические проблемы оценки непроизведенных активов в бухгалтерском учете и пути их решения //Бухгалтерский учет в бюджетных и некоммерческих организациях. 2017. № 8. С. 3-19.

10. Дружиловская Т.Ю. Проблемы применения справедливой стоимости в российском бухгалтерском учете // Сборник научных статей по бухгалтерскому учету, экономическому анализу и аудиту, посвященных юбилею заслуженного профессора ННГУ им. Н.И. Лобачевского, доктора экономических наук Е.А. Мизиковского. Нижний Новгород: ННГУ им. Н.И. Лобачевского. 2018. С. 98-103. [Электронный ресурc]. URL: https://elibrary.ru/item.asp?id=36059008 (дата обращения: 08.10.2019 г.).

11. Дружиловская Э.С. Первые федеральные стандарты бухгалтерского учета негосударственного сектора// Бухгалтерский учет в бюджетных и некоммерческих организациях. 2016. № 23. С. 2-16.

12. Колесник Н.Ф., Свешникова О.Н., Корж Я.В. Оценка нефинансовых активов через призму федеральных стандартов бухгалтерского учета для организаций государственного сектора // Экономические исследования и разработки. 2017. № 5. С.42-49.

13. Сборник: Международные стандарты финансовой отчетности общественного сектора: Издание 2010 г. Официальный перевод. 2012. [Электронный ресурc]. URL: https://www.minfin.ru/ru/ document/?id 4=16828 (дата обращения: 15.10.2019 г.).

14. Свешникова О.Н., Корж Я.В. Понятие и оценка основных средств в соответствии с международными стандартами финансовой отчетности общественного сектора // Татищевские чтения: актуальные проблемы науки и практики. 2018. С. 229-235

15. Свешникова О.Н., Корж Я.В. Материальные запасы бюджетных учреждений: реальность и перспективы стандартизации бухгалтерского учета для организаций государственного сектора // Вестник Евразийской науки. 2018. № 2; URL: https://esj.today/35ecvn218.html (дата обращения: 15.10.2019 г.). 